\title{
The role of oral contraceptive pills on increased risk of breast cancer in North West of Iran
}

\author{
Afsaneh Veisy* and Mariam Viga \\ Department of Midwifery, Mahabad Branch, Islamic Azad University, Iran
}

\begin{abstract}
Introduction: Breast cancer is the most common cancer in women, comprising a third of all cancers in women. Used by millions of women on daily basis, contraceptives are a potential risk in incidence of cancer. This study aimed to investigate the relationship between incidence of cancer and use of contraceptive pills.

Materials and methods: This is a retrospective analytical control-case study conducted on 235 breast cancer patients and 235 women in the control group. Data collection tools included a set of questions in the form of interviews and patients' medical records. Data were analyzed using statistical tests: t-test, Chi-square, Fisher, and Pearson Correlation Coefficient.
\end{abstract}

Results: The results indicated a significant relationship between breast cancer and history of contraceptive use, and also age at onset of use. However, the relationship between breast cancer and age at discontinuation of use, pattern of use, or interval since last use was insignificant.

Discussion and conclusion: The study results showed a significant relationship between breast cancer and contraceptive use (OR=2.11). Contraceptive use doubled the incidence of breast cancer. Findings of this study can be used as a guide for care and screening planning for contraceptive users.

\section{Introduction}

Cancer is a social problem. Of every 2 men 1 and of every 3 women 1 is exposed to cancer [1]. In every 4 cases of death, nearly 1 can be attributed to cancer [2]. Cancer is the cause of $12 \%$ of mortality worldwide [3]. In 2008, 12.7 million cases of cancer had been registered, and 7.6 million deaths occurred due to cancer [4]. Statistics reveal growing incidence rates of cancer, which have doubled in the past 30 years [5]. In Iran also, statistics indicate a huge increase in incidence of this disease [6].

Breast cancer is believed to be the most common cancer in women in the U.S., where 226870 new cases were diagnosed in 2012, and 110 people die of it every day [7]. Over the past 50 years, breast cancer has significantly increased in the U.S., and generally, it is believed that 1 out of every 7 women will have breast cancer in their early lives [8].

Statistics reveal a significant increase in this disease in the past 50 years, especially since 1970 . This increase has even been seen in countries like India, Japan, and Korea, which used to have the lowest rates of breast cancer [9]. Research results in Australia also confirm these findings, and they report its rates as 530 cases in 1982, which doubled by 2009 , with 37 new cases registered daily [10]. This disease is rapidly growing in China, Latin America, and Africa, and it has had a double or even triple increase in Malaysia and Singapore in recent decades [11].

Canadian researchers also believe that this increase is particularly seen in women younger than 50 years of age, and in recent decades, breast cancer has affected younger women [12]. In Iran, statistics reveal growing rates of breast cancer. It is reported that breast cancer mortality has increased by $150 \%$ in recent years, especially among women younger than 50 years old [13].
What causes breast cancer? And why a double and even triple increase is seen in recent decades? The Cancer Research Center consider reproductive factors such as age at menarche, age at menopause, parity, age at first delivery, and breast feeding influential [14]. A study in Iran noted its risk factors as low number of childbirths, short breastfeeding period, family history, and use of contraceptives [15]. A number of studies reported risk factors to include family history, early menarche, late menopause, and obesity at menopause [16].

Use of oral contraceptive pills, as a potential risk factor, has long attracted interest of researchers. Contraceptive pills were globally marketed in 1960 and were made available in Iran in 1973. Some researchers are concerned that this disease increases with onset of contraceptive pill use, so that in the U.S., as in most places in the world, the increase in breast cancer has coincided with onset contraceptive pill use. Pills are the most common means of contraception in the world and in Iran, used by millions of women [17]. Because of the prevalence of breast cancer and its prolonged latent phase, doctors and patients are concerned about the relationship between contraceptives and breast cancer.

The relationship between contraceptive pills and breast cancer incidence is controversial. A group of researchers concluded that use of contraceptive pills is related to and increases the incidence of breast cancer, and many reject such a relationship. The present study was conducted with the aim to determine the relationship between

${ }^{\star}$ Correspondence to: Afsaneh Veisy, Department of Midwifery, Mahabad Branch, Islamic Azad University, Mahabad, Iran, E-mail: a.veisy@yahoo.com

Key words: cancer, breast, oral contraceptive pills

Received: April 16, 2018; Accepted: June 12, 2018; Published: June 15, 2018 
breast cancer and use of contraceptive pills. Such studies are necessary owing to huge concerns expressed by the users and health personnel. Of course, it should be noted that conducting these studies will not lessen the value of contraceptive pills as one of the best contraception methods in unintended pregnancies and identifying groups at risk can more than ever clarify the value of contraception in these groups. Since breast cancer is diagnosed in late stages in developing countries, these studies will help early prevention and timely diagnosis and treatment in high-risk people.

\section{Method}

This is an analytical case-control study, in which the effects of risk factors on incidence of breast cancer were investigated. There were 235 subjects in each of the case and control groups.

1. Case group: Subjects in this group were selected by convenience sampling that attended chemotherapy and radiotherapy wards in Omid and Imam Khomaini hospitals in Urmia on daily basis. Objectives of the study were explained to the subjects, and they were interviewed after obtaining their permission. Each interview lasted 20 minutes.

2. Control group: Members for this group were selected through public call and from among samples attending women's clinics on daily basis. Breast examination was performed by a skillful physician. The subjects entered the study if healthy, and excluded if suspected, but were referred to relevant specialists for further examinations.

Necessary data were collected from both groups in relation to marital status, age, education, socio-economic status, history of breastfeeding, family history of cancer, history of benign mass, parity, age at menarche, regularity of menstrual cycle, use of contraceptive methods, history of diseases, history of alcohol use, history of hormone replacement therapy, history of infertility, duration of breastfeeding, use of cigarettes, history of chest radiography, and any contraindication for the pill, and then were matched with a higher number subjects in the control group. In this study, control and case groups were matched according to variables of age, socio-economic status, weight, and parity. Single women and those with history of first pregnancy after age of 25 years, history of chest radiography, family history of breast cancer, weighing over $80 \mathrm{~kg}$, lack of breast feeding, history of female infertility hormone treatment, alcohol and cigarette use were excluded from the study in both groups, and eventually, a number of women that did not match control group members were excluded.

Data were analyzed with SPSS-18 using Fisher's exact test, Chisquare, student t-test, and Pearson Correlation Coefficient, and significant level was considered less than 0.05 .

\section{Results}

Results showed most study subjects were in the 40-49 years age group. Mean age was 47.63 years in the case group and 46.45 years in the control group, (both groups were matched for age). Results also showed that the majority in the case group $(70.2 \%)$ and in the control group (52.8\%) used contraceptive pills. Chi-square test results revealed a significant difference between the two groups $(P=0.001)$ (Table 1$)$. In terms of duration of use, results showed mean duration of use was 94.54 in the case group and 100.2 in the control group. The difference between the two groups in duration of use was not significant (Table 2). In terms of age at onset of use, there was a significant difference between the use before and after age of 25 years in the case group, where chances of having breast cancer increased in the group that used the pills after 25 years old. In relation to type of pill used, the difference between two groups was significant, and the case people rather used HD or combined type (Table 2). In this study, no relationship was observed between cervical cancer and factors like age at discontinuation of the pill or pattern of use (regular or alternate use).

\section{Discussion}

Results of the study showed that use of contraceptive pills has doubled the incidence of breast cancer. In this study, mean age of subjects was 47.63 years. In a study by Shamsaldin, mean age of prevalence of breast cancer was 49.1 years [18], in Najafzadeh study [19] 49.18 years, and in Moosavi study 51.3 years [20]. In the West Azarbaijan province, age at diagnosis was lower compared to other regions in Iran.

In relation to type of contraception method used, the highest frequency related to contraceptive pills in both case and control groups ( $70.2 \%$ in case group and $52.8 \%$ in control). In studies by Veisy [21] and Brinton [22], pills had the highest frequency of use compared to other contraception methods.

The difference between the two groups in terms of history of use was significant. A study was conducted on 907 patients with breast cancer, comprising 731 whites and 176 blacks in the case group, and 1711 in the control group comprising 1152 whites and 559 blacks, in the interval from 1993 to 2007 . The two groups were studied in terms of history of contraceptive pill use and a significant relationship was observed between use of the pill and breast cancer [23]. Wang [24], Stanford [25], Fassell [26], and Commel [27] in their studies concluded that there was a significant relationship between history of contraceptive pill use and incidence of breast cancer. Another study by Marshi et al. conducted in Atlanta on 4575 patients with cancer (case group) and 4682 subjects (control group) with their age ranging from 35 to 65 years showed that use of contraceptive pills does not increase incidence of cancer and the difference between the two groups was insignificant [28]. While, in the study by Tavani [29] on 373 patients and control groups, younger than 40 years of age, no relationship was found between use of contraceptive pills and incidence of cancer. Whiteman [30], not only did not find use of the pill as a risk factor, but suggested use of the pill as a protective factor. However, age groups were indistinct in this study. Generally, in the present study use of contraceptive pills doubled the odds ratio of breast cancer $(\mathrm{OR}=2.11)$, with confidence interval of $95 \%$ (1.44-3.08). This risk level was found 2.2 in Isfahan province [31]. The odds ratio in the study by Shobairi [32] was found OR=2.83, and in the Powell study $\mathrm{OR}=3.02$ [33]. The odds ratio in the Italian research was $\mathrm{OR}=1.3$ [34].

Table 1. Absolute and relative frequency distribution of contraceptive methods and breast cancer.

\begin{tabular}{|c|c|c|c|c|c|c|c|}
\hline \multirow{2}{*}{$\begin{array}{l}\text { Group Contraceptive } \\
\text { method }\end{array}$} & \multicolumn{2}{|c|}{ Case } & \multicolumn{2}{|c|}{ Control } & \multicolumn{2}{|c|}{ Total } & \multirow{2}{*}{ Result } \\
\hline & Number & Percent & Number & Percent & Number & Percent & \\
\hline OCP & 165 & 70.2 & 124 & 52.8 & 289 & 61.5 & $\chi^{2}=33.69$ \\
\hline Others & 63 & 26.8 & 92 & 39.1 & 155 & 32.95 & $P=0.001$ \\
\hline None & 7 & 3.0 & 19 & 8.1 & 26 & 5.55 & $\mathrm{df}=2$ \\
\hline
\end{tabular}


Table 2. Risk of breast cancer according to the use of combination oral contraceptives.

\begin{tabular}{|c|c|c|c|c|c|c|c|}
\hline \multirow{2}{*}{$\begin{array}{c}\text { Group } \\
\text { Pill users }\end{array}$} & \multicolumn{2}{|c|}{ Case } & \multicolumn{2}{|c|}{ Control } & \multicolumn{2}{|c|}{ OR } & \multirow[t]{2}{*}{ CI $95 \%$} \\
\hline & Number & Percent & Number & Percent & & & \\
\hline OCP & 165 & 70.2 & 124 & 52.8 & \multirow{3}{*}{2.11} & \multirow{3}{*}{$1.44-3.08$} & \multirow{3}{*}{$p=0.001$} \\
\hline Others & 63 & 26.8 & 92 & 39.1 & & & \\
\hline None & 7 & 3 & 19 & 8.1 & & & \\
\hline$<12$ & 29 & 6.17 & 12 & 6.9 & 60.2 & $1.31-3.01$ & \multirow{4}{*}{$p=0.219$} \\
\hline $13-60$ & 52 & 5.31 & 44 & 5.35 & 23.1 & $0.78-93.1$ & \\
\hline $61-96$ & 17 & 3.1 & 11 & 9.8 & 58.1 & $0.72-3.46$ & \\
\hline$\geq 97$ & 67 & 6.4 & 57 & 0.46 & 33.1 & $0.88-2.02$ & \\
\hline \multicolumn{7}{|c|}{ Age at onset of using OCP } & \multirow{5}{*}{$p=0.0001$} \\
\hline $13-18$ & 20 & 12.5 & 22 & 17.7 & 0.88 & $0.44-1.61$ & \\
\hline $19-24$ & 64 & 38.5 & 69 & 55.7 & 0.9 & $0.61-1.34$ & \\
\hline $25-30$ & 50 & 31.2 & 28 & 22.6 & 1.99 & $1.20-3.30$ & \\
\hline$>30$ & 29 & 17.8 & 5 & 4 & 6.47 & $2.46-17.04$ & \\
\hline \multicolumn{7}{|c|}{ Age at discontinuing OCP } & \multirow{6}{*}{$p=0.004$} \\
\hline$<25$ & 20 & 12.1 & 25 & 20.2 & 0.78 & $0.42-1.44$ & \\
\hline $25-34$ & 47 & 28.4 & 43 & 34.6 & 1.11 & $0.75-1.76$ & \\
\hline $35-44$ & 51 & 31 & 32 & 25.8 & 1.75 & $1.08-2.85$ & \\
\hline$>45$ & 24 & 14.5 & 8 & 6.5 & 3.22 & $1.41-7.34$ & \\
\hline Don't know & 23 & 14 & 16 & 12.9 & & - & \\
\hline \multicolumn{7}{|c|}{ Time since last use } & \multirow{5}{*}{$p=0.315$} \\
\hline $12>$ & 25 & 15.15 & 11 & 8.87 & 2.42 & $1.63-5.04$ & \\
\hline Dec-36 & 17 & 10.31 & 7 & 5.65 & 2.54 & $1.03-6.24$ & \\
\hline $37-96$ & 37 & 22.42 & 25 & 20.16 & 1.65 & $0.91-2.70$ & \\
\hline$>97$ & 86 & 52.12 & 81 & 65.32 & 1.09 & $0.75-1.60$ & \\
\hline LD & 116 & 70.3 & 106 & 85.4 & 1.18 & $0.82-1.70$ & \multirow{2}{*}{$p=0.002$} \\
\hline HD & 49 & 29.7 & 20 & 14.6 & 2.83 & $1.62-4.93$ & \\
\hline Used & 165 & 2.70 & 124 & 8.52 & \multirow{2}{*}{11.2} & \multirow{2}{*}{$1.44-3.08$} & \multirow{2}{*}{$p=0.001$} \\
\hline Didn't use & 70 & 8.29 & 111 & 2.47 & & & \\
\hline
\end{tabular}

In this study, increased duration of use did not increase odds ratio of cervical cancer, and no relationship was found between duration of use and incidence of breast cancer. Kelsey [35] believes prolonged use increases the risk. Stanford et al. found relative risk of 2.2 with more than 10 years duration of use [25].

In the case group, in terms of onset of use, the difference between use before and after age of 25 years was significant and use after 25 years of age showed greater odds ratio of affliction. In the study by Faramni, the odds ratio was higher in patients that had used the pill after 40 years of age [36]. Betties et al. in a study on the effect of age at onset of use of the pill on incidence of breast cancer concluded that women that had started using the pill before 18 years of age contracted cancer 4 years earlier [37]. Harland [38] and Whiteman [30] found no relationship between age at onset of use of the pill and incidence of cancer. In Iran, childbirth occurs at younger ages, and use of the pill is rare before the age of 20 . The difference in age at first childbirth and use of contraceptive methods before 20 years of age between Iran and other countries can influence the above results.

In this study, the relationship between type of contraceptive pill and incidence of breast cancer was significant. In the case group, use of HD was higher, and those that had received higher doses of estrogen had higher odds. Illiasen [39], in a study on concentration of hormones and breast cancer concluded that higher levels of estrogen are observed in women with breast cancer. A number of studies have also investigated the role of progesterone. In the study by Alaskar there was a significant relationship between incidence of cancer and progesterone. In this study, variety of pills used contained same amount of progesterone, but rather varied in amounts of estrogen. The difference between two groups in age at discontinuation of the pill was insignificant. Also, in terms of regularity (regular daily use) and persistence (permanent or alternate use) in the use of the pill, the difference between two groups was insignificant.

\section{Conclusion}

Results of the study showed that use of contraceptive pills doubles incidence of breast cancer. Hence, breast cancer screening programs are necessary in Iran.

Results of this study indicate that women that use contraceptive pills have greater needs for preventive and screening measures.

\section{References}

1. Miller KD, Siegel RL, Lin CC, Mariotto AB, Kramer JL, et al. (2016) Cancer treatment and survivorship statistics, 2016. CA Cancer J Clin 66: 271-289. [Crossref]

2. Siegel R, Ward E, Brawley O, Jemal A (2011) Cancer statistics, 2011: the impact of eliminating socioeconomic and racial disparities on premature cancer deaths. $C A$ Cancer J Clin 61: 212-236. [Crossref]

3. Emami Razavi SH, Aaghajani H, Haghazali M, Nadali F, Ramazani R, et al. (2009) The Most Common Cancers in Iranian Women. Iranian J Publ Health 38: 109-112.

4. Siegel RL, Miller KD, Jemal A (2015) Cancer statistics. CA Cancer J Clin 65:5-29. [Crossref]

5. Harirchi I, Kolahdoozan S, Karbakhsh M, Chegini N, Mohseni SM, et al. (2011) Twenty years of breast cancer in Iran: downstaging without a formal screening program. Ann Oncol 22: 93-97. [Crossref]

6. Hashemzadeh S, Aligholipour Maleki R, Golzari SE (2012) The incidence of breast cancer in northwest iran (2003 -2008). J Cardiovasc Thorac Res 4: 5-9. [Crossref]

7. Landis MD, Lehmann BD, Pietenpol JA, Chang JC (2013) Patient-derived breast tumor xenografts facilitating personalized cancer therapy. Breast Cancer Res 15: 201. [Crossref]

8. Berek JS. TEXST BOOK OF Gynecology: (2012). 
9. Beiki O, Hall P, Ekbom A, Moradi T (2012) Breast cancer incidence and case fatality among 4.7 million women in relation to social and ethnic background: a populationbased cohort study. Breast Cancer Res 6:14: R5. [Crossref]

10. Australian Institute of Health and Welfare \& Australasian Association of Cancer Registries. (2012) Cancer in Australia: an overview: Cancer series no: 74.

11. Bhoo-Pathy N, Hartman M, Yip CH, Saxena N, Taib NA, et al. (2012) Ethnic differences in survival after breast cancer in South East Asia. PLoS One 7: e30995. [Crossref]

12. Merlo DF, Ceppi M, Filiberti R, Bocchini V, Znaor A, et al. (2012) Breast cancer incidence trends in European women aged 20-39 years at diagnosis. Breast Cancer Res Treat 134: 363-370. [Crossref]

13. Taghavi A, Fazeli Z, Vahedi M, Baghestani AR, Pourhoseingholi A, et al. (2012) Increased trend of breast cancer mortality in Iran. Asian Pac J Cancer Prev 13: 367370. [Crossref]

14. Collaborative Group on Hormonal Factors in Breast Cancer1 (1996) Breast cancer and hormonal contraceptives: collaborative reanalysis of individual data on 53297 women with breast cancer and 100239 women without breast cancer from 54 epidemiological studies. Lancet 347: 1713-1727. [Crossref]

15. Ghiasvand R, Maram ES, Tahmasebi S, Tabatabaee SH (2011) Risk factors for breas cancer among young women in southern Iran. Int J Cancer 129: 1443-1449. [Crossref]

16. Pakseresht S, Ingle GK, Bahadur AK, Ramteke VK, Singh MM, et al. (2009) Risk factors with breast cancer among women in Delhi. Indian J Cancer 46: 132-138. [Crossref]

17. Shakerinejad G, Hidarnia A, Motlagh ME, Khodabakhsh Karami K, Niknami SH, et al. (2013) Factors predicting mood changes in oral contraceptive pill users Reproductive Health. J Res Med Sci 17: 344-347. [Crossref]

18. El Saghir NS, Shamseddine AI, Geara F, Bikhazi K, Rahal B, et al. (2002) Age distribution of breast cancer in Lebanon: increased percentages and age adjusted incidence rates of younger-aged groups at presentation. J Med Liban 50: 3-9. [Crossref]

19. Bambara HA, Zouré AA, Sawadogo AY, Ouattara AK, Ouédraogo NLM, Traoré SS, et al. (2017) Breast cancer: descriptive profile of 80 women attending breast cancer care in the Department of General and Digestive Surgery of CHU-YO. Pan Afr Med J 28: 314. [Crossref]

20. Mousavi SM, Mohaghegghi MA, Mousavi-Jerrahi A, Nahvijou A, Seddighi Z (2006) Burden of breast cancer in Iran: a study of the Tehran population-based cancer registry. Asian Pac J Cancer Prev 7: 571-574. [Crossref]

21. Vessey M, Painter R (2006) Oral contraceptive use and cancer. Findings in a large cohort study, 1968-2004. Br J Cancer 95: 385-389. [Crossref]

22. Brinton LA, Reeves WC, Brenes MM, Herrero R, de Britton RC, et al. (1990) Oral contraceptive use and risk of invasive cervical cancer. Int $J$ Epidemiol 19: 4-11. [Crossref]

23. Rosenberg L, Zhang Y, Coogan PF, Strom BL, Palmer JR (2009) A case-control study of oral contraceptive use and incident breast cancer. Am J Epidemiol 169: 473-479. [Crossref]
24. Wang QS, Ross RK, Yu MC, Ning JP, Henderson BE, et al. (1992) A case-control study of breast cancer in Tianjin, China. Cancer Epidemiol Biomarkers Prev 1: 435439. [Crossref]

25. Brinton LA, Daling JR, Liff JM, Schoenberg JB, Malone KE, et al. (1995) Ora contraceptives and breast cancer risk among younger women. $J$ Natl Cancer Inst 87 827-835. [Crossref]

26. Fasal E, Paffenbarger RS Jr (1975) Oral contraceptives as related to cancer and benign lesions of the breast. J Natl Cancer Inst 55: 767-773. [Crossref]

27. Kumle M, Weiderpass E, Braaten T, Persson I, Adami HO, et al. (2002) Use of ora contraceptives and breast cancer risk: The Norwegian-Swedish Women's Lifestyle and Health Cohort Study. Cancer Epidemiol Biomarkers Prev 11: 1375-1381. [Crossref]

28. Marchbanks PA, McDonald JA, Wilson HG, Folger SG, Mandel MG, et al. (2002) Ora contraceptives and the risk of breast cancer. $N$ Engl J Med 346: 2025-2032. [Crossref]

29. Tavani A, Negri E, Franceschi S, Parazzini F, La Vecchia C (1993) Oral contraceptives and breast cancer in northern Italy. Final report from a case-control study. $\mathrm{Br} J$ Cancer 68: 568-571. [Crossref]

30. Wingo PA, Austin H, Marchbanks PA, Whiteman MK, Hsia J, et al. (2007) Ora contraceptives and the risk of death from breast cancer. Obstet Gynecol 110: 793-800. [Crossref]

31. Ehsanpour S, Ahmadi Nejad FS, Rajabi F, Taleghani F (2013) Investigation on the association between breast cancer and consumption patterns of combined oral contraceptive pills in the women of Isfahan in 2011. Iran J Nurs Midwifery Res 18: 186-190. [Crossref]

32. Tehranian N, Shobeiri F, Pour FH, Hagizadeh E (2010) Risk factors for breast cancer in Iranian women aged less than 40 years. Asian Pac J Cancer Prev 11: 1723-1725. [Crossref]

33. Lodha R, Joshi A, Paul D, Lodha KM, Nahar N, et al. (2011) Association between reproductive factors and breast cancer in an urban set up at central India: a case-control study. Indian J Cancer 48: 303-307. [Crossref]

34. La Vecchia C, Negri E, Franceschi S, Talamini R, Amadori D, et al. (1995) Oral contraceptives and breast cancer: a cooperative Italian study. Int J Cancer 60: 163-167. [Crossref]

35. Kelsey JL, Gammon MD, John EM (1993) Reproductive factors and breast cancer. Epidemiol Rev 15: 36-47. [Crossref]

36. Brinton LA, Hoover R, Szklo M, Fraumeni JF Jr (1982) Oral contraceptives and breas cancer. Int J Epidemiol 11: 316-322. [Crossref]

37. Imkampe AK1, Bates T (2012) Correlation of age at oral contraceptive pill start with age at breast cancer diagnosis. Breast $J$ 18: 35-40. [Crossref]

38. Eliassen AH, Missmer SA, Tworoger SS, Spiegelman D, Barbieri RL, et al. (2006) Endogenous steroid hormone concentrations and risk of breast cancer among premenopausal women. J Natl Cancer Inst 98: 1406-1415. [Crossref]

39. Dumeaux V, Alsaker E, Lund E (2003) Breast cancer and specific types of ora contraceptives: a large Norwegian cohort study. Int J Cancer 105: 844-850. [Crossref]

Copyright: (C2018 Veisy A. This is an open-access article distributed under the terms of the Creative Commons Attribution License, which permits unrestricted use, distribution, and reproduction in any medium, provided the original author and source are credited. 